\title{
Prevalence and factors associated with non-adherence to multi-drug resistant tuberculosis (MDR-TB) treatment at Mulago National Referral Hospital, Kampala, Uganda
}

\author{
Charles Batte, ${ }^{1,2,3}$, Martha S Namusobya,${ }^{3}$ Racheal Kirabo, ${ }^{4}$ John Mukisa ${ }^{4}$, \\ Susan Adakun ${ }^{3}$, Achilles Katamba ${ }^{2,4}$
}

1. School of Medicine, University of Liverpool.

2. Uganda Tuberculosis Implementation Research Consortium.

3. Lung Institute, Makerere University College of Health Science.

4. Clinical Epidemiology Unit, Makerere University College of Health Sciences.

\section{Emails:}

batchaux@gmail.com; martharynam@gmail.com; rachealkora@gmail.com; jmukisa90@gmail.com; adakunsusan@gmail.com; axk95@case.edu

\begin{abstract}
Background: In Uganda, $12 \%$ of previously treated TB cases and 1.6\% of new cases have MDR-TB and require specialized treatment and care. Adherence is crucial for improving MDR-TB treatment outcomes. There is paucity of information on the extent to which these patients adhere to treatment and what the drivers of non-adherence are.

Methods: We conducted a cohort study using retrospectively collected routine program data for patients treated for MDRTB between January 2012 - May 2016 at Mulago Hospital. We extracted anonymized data on non-adherence (missing 10\% or more of DOT), socio-economic, demographic, and treatment characteristics of the patients. All participants were sensitive to MDR-TB drugs after second line Drug Susceptible Testing (DST) at entry into the study. Factors associated with non-adherence to MDR-TB treatment were determined using generalized linear models for the binomial family with log link and robust standard errors. We considered a p- value less than 0.05 as statistically significant.

Results: The records of 227 MDR- TB patients met the inclusion criteria, 39.4\% of whom were female, $32.6 \%$ aged between $25-34$ years, and $54.6 \%$ living with HIV/AIDS. About $11.9 \%$ of the patients were non-adherent. The main driver for non-adherence was history of previous DR-TB treatment; previously treated DR-TB patients were 3.46 (Adjusted prevalence ratio: 3.46, $95 \%$ CI: 1.68 - 7.14) times more likely to be non-adherent.

Conclusion: One in $10 \mathrm{MDR}-\mathrm{TB}$ patients treated at Mulago hospital is non-adherent to treatment. History of previous DRTB treatment was significantly associated with non-adherence in this study. MDR-TB program should strengthen adherence counselling, strengthen DST surveillance, and close monitoring for previously treated DR-TB patients.

Keywords: Non-adherence, multi-drug resistant tuberculosis, treatment.

DOI: https://dx.doi.org/10.4314/ahs.v21i1.31

Cite as: Batte C, Namusobya MS, Kirabo R, Mukisa J, Adakun S, Katamba A. Prevalence and factors associated with nonadberence to multi-drug resistant tuberculosis (MDR-TB) treatment at Mulago National Referral Hospital, Kampala, Uganda. Afri Health Sci. 2021;21(1):238-47. bttps:// dx.doi.org/10.4314/abs.v21i1.31
\end{abstract}

\section{Introduction}

Multi Drug Resistant / Rifampicin Resistant TB (MDR$\mathrm{TB} / \mathrm{RR}-\mathrm{TB})$ is one of the global public health prob-

\section{Corresponding author: \\ Charles Batte, \\ Makerere University Lung Institute \\ Upper Mulago Hill, PO BOX 7072, \\ Kampala, Uganda \\ Tel: +256700800618 \\ Email: batchaux@gmail.com}

lems. It remains a priority for the World health Organization through the End Tby 2030 strategy ${ }^{1}$. In 2018 alone, 186,772 cases of MDR-TB/RR were detected and notified globally ${ }^{3,5}$. During the same year, Africa registered an estimated MDR-TB/RR-TB incidence rate of 7.3 per 100000 population ${ }^{5}$. Uganda remains a high-burden country with $12 \%$ of previously treated TB cases and $1 \%$ of new cases having MDR-TB ${ }^{5}$. With the high MDR-TB/RR-TB numbers prompt diagnosis, start, and adherence to treatment by patients is key. MDR-TB treatment is difficult, complex and prolonged properly cited. 
(with an approximate duration of 18 to 24 months). It is also expensive with an estimated treatment cost of greater than 40 times that of drug susceptible TB especially in resource limited countries ${ }^{7}$.

Daily Injectable aminoglycosides form the backbone of MDR-TB treatment regimens and their prolonged use is associated with better treatment outcomes ${ }^{6}$. Current recommendations approve the use of aminoglycosides for eight months during the intensive phase of MDRTB treatment ${ }^{8}$. However, aminoglycosides are associated with adverse events that include hearing loss which can be permanent and may also affect the quality of life of patients who may be cured of MDR-TB but face life-long disability ${ }^{9}$. Other adverse events due to MDRTB treatment include; renal failure and nerve damage ${ }^{10}$. These adverse effects combined with the long treatment period and cost to the patients immensely affect patients' adherence to treatment and therefore, treatment outcomes.

Despite TB being a curable disease, $\geq 90 \%$ patient adherence to anti-TB treatment is required to achieve $\mathrm{it}^{11}$. In Uganda, the burden of non-adherence among patients with drug susceptible TB is high ${ }^{12}$. Non-adherence has been associated with medication drug side effects, length of treatment, pill burden, and the economic impact of accessing TB treatment (especially when directly observed). In a study done at Mulago National Referral Hospital ${ }^{13}$, it was found that $59 \%$ of patients with drug susceptible Tuberculosis had poor treatment outcomes such as treatment failure, loss to follow-up and death. No previous study has however, been done among MDR-TB patients. Non-adherence to medication results into treatment failure, TB relapse, and development of multi-drug-resistant TB (MDRTB) and extensively drug-resistant TB (XDR-TB), the emergence of which represents an unprecedented public health emergency ${ }^{14}$.

An understanding of the factors associated with non-adherence to MDR-TB treatment is imperative in generating evidence that can inform and guide development of programs and initiatives to improve adherence patterns, MDR-TB treatment outcomes and ending TB. In this paper, we present the prevalence and factors associated with non-adherence to MDR-TB treatment using secondary data from Mulago National Referral Hospitalthe largest MDR-TB treatment center in Uganda.

\section{Methods}

\section{Study Design}

We conducted a cohort study using secondary data from patients' records (treatment files) at Mulago National Referral Hospital (MNRH) TB center. The use of secondary data allows for the analysis of large sets of routinely collected data at low cost ${ }^{15}$.

\section{Setting}

MNRH TB center registers between 50-70 new MDRTB patients per year under the Uganda National Tuberculosis and Leprosy Program (NTLP). It is one of the 13 MDR-TB treatment centers across the country where new MDR-TB patients are referred and treated. $\mathrm{T} / \mathrm{span}>$ rained health workers and treatment supporters carry out Directly Observed Therapy (DOT) for the patients. The health worker maintains a drug record chart for each administered dose of the MDRTB drugs and provides adherence counselling to each patient. Clinical data are manually collected using the patients' treatment card and entered into three National registers; the presumptive TB register, the laboratory register, and the treatment register. It includes; the name of the patient, age, sex, HIV status, marital status, date of clinic attendance, date of sputum submission, results of sputum smear, results of the Gene Xpert test, TB diagnosis, type of treatment and treatment regimen. At a periodic basis, all the data from the 13 MDR-TB treatment centers is entered into the NTLP's electronic database hosted at the Ministry of health, while the physical records (back-up hard copies) including MDRTB patient's cards (after completion of treatment) are stored at the MNRH TB center. Before commencing of MDR-TB treatment, all patients are evaluated for sensitivity to current MDR-TB drugs after second line Drug Susceptibility Testing (DST) to rule out X-DR TB. However, due to personnel and logistical challenges, this electronic database was not current at the time of the study. We, therefore, only considered patient files from MNRH TB center for data abstraction in order to meet the objectives of our study.

We estimated the sample size using the Kish Leslie (1965) formula by assuming the prevalence of non-adherence among DR-TB patients $32.7 \%$ as reported in South Africa ${ }^{16}, 254$ participants would give the prevalence of non-adherence with a $95 \%$ confidence and 5 $\%$ margin of error. However, because of incompleteness of routinely collected data, we were only able to collect 227 participant charts for analysis in this study.

\section{Study population}

We considered the records of all MDR-TB patients treated at MNRH TB unit between January 2012 and 
May 2016. We extracted participants' data from the start to end of their MDR-TB treatment for the period under review. The length of the records included ranged between 18- 24 months (varied according to the prescribed duration of treatment by the attending physician) of treatment. We excluded records of the patients with missing data on key independent variables like age, sex, treatment category, HIV status, previous TB treatment from the final analysis.

\section{Study procedure}

After obtaining ethical clearance from the IRB and permission from the NTLP, the principal investigator accessed the electronic MDR-TB register, abstracted data from the charts where possible, and set up the dataset as informed by the variables under consideration in this study.

\section{Data quality control}

A data extraction questionnaire was pretested on less than $5 \%$ of the sample size and adjustments made before conducting final data collection. Fifteen records were ineligible because of missing data. The excluded and included records had negligible difference in non-adherence levels.

\section{Data analysis}

In preparing for data analysis, we merged all data to create a final data set. Database access was locked on the 15th September 2016 permitting no further edits. The raw data set was imported into STATA version 14.0 for analysis (College station, Texas, USA). We computed means, medians, standard deviations and interquartile ranges for continuous variables; proportions and percentages for categorical variables. Non- adherence was defined as a patient missing $\geq 10 \%$ of the total prescribed dose over the 18-24 months of treatment ${ }^{14,17}$. The prevalence of non- adherence was calculated as a proportion defined as the number of individuals that were non-adherent divided by the total number of participants included in the study.
We evaluated the factors associated with non-adherence to MDR-TB treatment using generalized linear models for the binomial family with a log link and robust standard errors. Factors with p value less than 0.25 and potential confounding variables were considered for multivariable regression analysis. We formed two-way interaction terms between the variables to assess for interaction. The crude and adjusted prevalence ratios and their $95 \%$ confidence intervals were calculated. A p-value of less than 0.05 was considered statistically significant.

\section{Ethical consideration}

The School of Biomedical Sciences - Higher Degrees Research and Ethics Committee (SBS-HDREC \#549), approved the study protocol and a waiver of informed consent while Mulago Hospital Research Ethics Committee (MHREC) granted administrative approval. MNRH and NTLP granted final permission to the study team to access the patient records the before final data extraction. We maintained confidentiality of the patients' data by using anonymized extracted data for further analysis.

\section{Results \\ Socio-economic and treatment characteristics of participants}

Eighty-nine $(34.9 \%)$ of the participants were female, seventy-four $(32.6 \%)$ were aged between 25 and 34 years of age and 80/227 (38.5\%) were married. About $65.1 \%$ of the participants were employed and one hundred eighteen (52\%) lived in rural settings.

One hundred twenty-four $(54.6 \%)$ of the participants were co-infected with HIV while one hundred fifty-one (66.5\%) had had TB treatment before (Table 2).

\section{Non-adherence to MDR-TB treatment}

Of the 227 patients with MDR-TB, 27 (11. 9\%, $95 \% \mathrm{CI}$ : 8.2-16.8) were non-adherent to treatment (Figure 1). 
Table 1: Socio-demographic characteristics of the study participants with MDR-TB at Mulago National Referral Hospital January 2012-May 2016, N=227

\begin{tabular}{lll}
\hline Variable & Frequency, N & Percentage \% \\
\hline Sex* & 89 & 39.4 \\
Female & 137 & 60.6 \\
Male & & \\
Age group & 5 & 2.2 \\
$0-14$ & 62 & 27.3 \\
$15-24$ & 74 & 32.6 \\
$25-34$ & 53 & 23.4 \\
$35-44$ & 26 & 11.5 \\
$45-54$ & 7 & 3.1 \\
$>54$ & & \\
Marital status & & \\
Married & 80 & 38.5 \\
Separated & 32 & 15.4 \\
Single & 87 & 41.8 \\
Widowed & 9 & 4.3 \\
Employment & & \\
No & 109 & 34.9 \\
Yes & 76 & 65.1 \\
Residence & 142 & 58.0 \\
Urban & & \\
Rural & 18.0 \\
\hline
\end{tabular}

*1 missing sex variable, ${ }^{* *} 19$ missing marital status, ${ }^{* *} 9$ missing employment status 
Table 2: Treatment characteristics of study participants with MDR-TB at Mulago National Referral Hospital TB unit, January 2012-May 2016, N=227

\begin{tabular}{|c|c|c|}
\hline Variable & $\begin{array}{l}\text { Frequency, } \\
\mathbf{N}\end{array}$ & $\begin{array}{l}\text { Percentage } \\
\%\end{array}$ \\
\hline \multicolumn{3}{|l|}{ HIV Status } \\
\hline Negative & 103 & 45.4 \\
\hline Positive & 124 & 54.6 \\
\hline \multicolumn{3}{|l|}{ On ART* } \\
\hline No & 105 & 46.3 \\
\hline Yes & 122 & 53.7 \\
\hline \multicolumn{3}{|l|}{ Treatment registration group } \\
\hline New $(N)$ & 79 & 34.8 \\
\hline Relapse (Rp) & 39 & 17.2 \\
\hline After loss to follow-up (Rt) & 30 & 13.2 \\
\hline After failure of first treatment with first-line drugs (F1) & 41 & 18.1 \\
\hline After failure of retreatment regimen with first line drugs (F2) & 35 & 15.4 \\
\hline After failure of regimen with second-line drugs (F4) & 1 & 0.4 \\
\hline Other / previously treated without known outcome(o) & 2 & 0.9 \\
\hline \multicolumn{3}{|l|}{ Previous TB** Treatment } \\
\hline No & $76^{\mathrm{a}}$ & 33.5 \\
\hline Yes & 151 & 66.5 \\
\hline \multicolumn{3}{|l|}{ Previous DR-TB ${ }^{\star *}$ Treatment } \\
\hline No & 208 & 91.6 \\
\hline Yes & 19 & 8.4 \\
\hline \multicolumn{3}{|l|}{ Comorbidities } \\
\hline No & 87 & 38.3 \\
\hline Yes & 140 & 61.7 \\
\hline \multicolumn{3}{|l|}{ Adverse Events } \\
\hline No & 168 & 74 \\
\hline Yes & 59 & 26 \\
\hline \multicolumn{3}{|l|}{ Month of Sputum Conversion ${ }^{* * * *}$} \\
\hline 0 - 2 months & 85 & 41.5 \\
\hline$>2$ months & 51 & 24.9 \\
\hline Unable to produce sputum & 69 & 33.7 \\
\hline
\end{tabular}

\section{Pie chart showing the non Aherence status of the study participants}

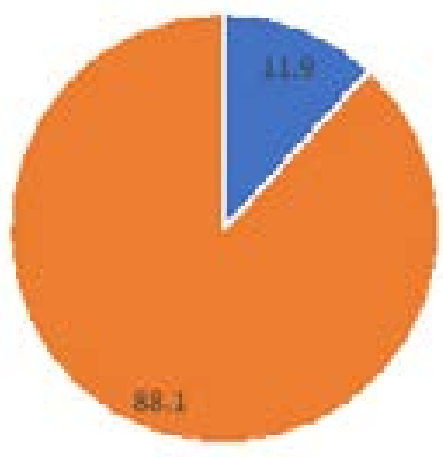

- Non adherent = Adherent

Figure 1. 
Factors associated with Non-adherence to MDRTB treatment

At regression analysis, a previous history of DR-TB treatment and the treatment registration group were significantly associated with non-adherence to treatment (Table 3 and 4).

Table 3: Regression analysis for socio-demographic characteristics and association with non-adherence to MDR-TB treatment at Mulago National Referral Hospital TB unit, January 2012-May 2016, N=227

\begin{tabular}{|c|c|c|c|c|}
\hline Characteristic & $\begin{array}{c}\text { Non } \\
\text { adherent, } \\
\mathbf{N}(\%) \\
\end{array}$ & $\begin{array}{c}\text { Adherent } \\
\mathbf{N}(\%)\end{array}$ & $\begin{array}{c}\text { Crude prevalence } \\
\text { ratios }(95 \% \\
\text { Confidence intervals) }\end{array}$ & P-value \\
\hline \multicolumn{5}{|c|}{, } \\
\hline Male & $8(30.8)$ & $81(40.5)$ & I & \\
\hline Female & $18(69.2)$ & $119(59.5)$ & $1.46(0.66-3.22)$ & 0.347 \\
\hline \multicolumn{5}{|l|}{$\begin{array}{l}\text { Age group (in } \\
\text { years) }\end{array}$} \\
\hline $0-14$ & $1(3.7)$ & $4(2.0)$ & 1 & \\
\hline $15-24$ & $5(18.5)$ & $57(28.5)$ & $0.57(0.06-2.83)$ & 0.361 \\
\hline $25-34$ & $13(48.2)$ & $61(30.5)$ & $0.88(0.14-5.45)$ & 0.889 \\
\hline $35-44$ & $5(18.5)$ & $48(24.0)$ & $0.47(0.07-3.30)$ & 0.449 \\
\hline $45-54$ & $2(7.4)$ & $24(12.0)$ & $0.38(0.04-3.49)$ & 0.396 \\
\hline$>54$ & $1(8.7)$ & $6(3.0)$ & $0.71(0.06-8.95)$ & 0.794 \\
\hline \multicolumn{5}{|l|}{ Marital Status** } \\
\hline Married & $9(34.6)$ & $71(39.0)$ & 1 & \\
\hline Separated & $6(23.1)$ & $26(14.3)$ & $1.67(0.64-4.31)$ & 0.292 \\
\hline Single & $10(38.5)$ & $77(42.3)$ & $1.02(0.44-2.39)$ & 0.960 \\
\hline Widowed & $1(3.9)$ & $8(4.4)$ & $0.99(0.14-6.96)$ & 0.990 \\
\hline \multicolumn{5}{|l|}{ Employment $^{* * *}$} \\
\hline No & $11(40.7)$ & $65(34.0)$ & 1 & \\
\hline yes & $16(59.6)$ & $126(66.0)$ & $0.78(0.38-1.59)$ & 0.494 \\
\hline \multicolumn{5}{|l|}{ Residence } \\
\hline Urban & $12(44.4)$ & $97(48.5)$ & 1 & \\
\hline Rural & $15(55.6)$ & $103(51.5)$ & $0.83(0.33-2.05)$ & 0.678 \\
\hline
\end{tabular}


Table 4: Regression analysis of treatment characteristics and association with non-adherence to MDR-TB treatment at Mulago National Referral Hospital TB unit January 2012-May 2016, N=227

\begin{tabular}{|c|c|c|c|c|}
\hline Characteristic & $\begin{array}{c}\text { Non } \\
\text { adherent, } \\
\mathrm{N}(\%)\end{array}$ & $\begin{array}{c}\text { Adherent } \\
\mathrm{N}(\%)\end{array}$ & $\begin{array}{c}\text { Crude prevalence } \\
\text { ratios }(95 \% \\
\text { Confidence intervals) }\end{array}$ & $\begin{array}{c}\mathrm{P}- \\
\text { value }\end{array}$ \\
\hline \multicolumn{5}{|l|}{ HIV status } \\
\hline Negative & $10(37.0)$ & $93(46.5)$ & 1 & \\
\hline Positive & $17(63.0)$ & $\begin{array}{c}107 \\
(53.5)\end{array}$ & $1.41(0.68-2.95)$ & 0.359 \\
\hline \multicolumn{5}{|l|}{ On ART } \\
\hline No & $10(37.0)$ & 95 (47.5) & 1 & \\
\hline Yes & $17(63.0)$ & $\begin{array}{c}105 \\
(52.5)\end{array}$ & $1.46(0.70-3.06)$ & 0.312 \\
\hline \multicolumn{5}{|l|}{$\begin{array}{l}\text { Treatment } \\
\text { registration } \\
\text { group }\end{array}$} \\
\hline New & $9(33.3)$ & $70(35.0)$ & 1 & \\
\hline Relapse & $2(7.4)$ & 37 (18.5) & $0.45(0.10-1.99)$ & 0.293 \\
\hline $\begin{array}{l}\text { After loss to } \\
\text { follow up }\end{array}$ & $8(29.6)$ & $22(11.0)$ & $2.34(0.99-5.51)$ & 0.052 \\
\hline $\begin{array}{l}\text { After failure of } \\
\text { first treatment } \\
\text { with first line } \\
\text { drugs }\end{array}$ & $2(7.4)$ & $33(16.5)$ & $0.50(0.11-2.21)$ & 0.362 \\
\hline $\begin{array}{l}\text { After failure of } \\
\text { regimen with } \\
\text { second line drugs } \\
\text { and others }\end{array}$ & $2(7.4)$ & $1(0.5)$ & $5.85(2.13-16.1)$ & $0.001^{* * *}$ \\
\hline \multicolumn{5}{|l|}{$\begin{array}{l}\text { Previous TB } \\
\text { treatment }\end{array}$} \\
\hline No & $8(29.6)$ & $68(34.0)$ & 1 & \\
\hline Yes & $19(70.4)$ & $\begin{array}{c}132 \\
(66.0)\end{array}$ & $1.19(0.55-2.61)$ & 0.654 \\
\hline \multicolumn{5}{|l|}{$\begin{array}{l}\text { Previous DR-TB } \\
\text { treatment }\end{array}$} \\
\hline No & $19(70.4)$ & $\begin{array}{c}189 \\
(94.5)\end{array}$ & 1 & \\
\hline $\begin{array}{l}\text { Yes } \\
\text { Comorbidities }\end{array}$ & 8 (29.6) & $11(5.5)$ & $4.61(2.33-9.11)$ & $<0.001^{*}$ \\
\hline No & $8(29.6)$ & $79(39.5)$ & 1 & \\
\hline Yes & $19(70.4)$ & $\begin{array}{c}121 \\
(60.5)\end{array}$ & $1.47(0.67-3.23)$ & 0.330 \\
\hline \multicolumn{5}{|l|}{ Adverse events } \\
\hline No & $22(81.5)$ & $\begin{array}{c}146 \\
(73.0)\end{array}$ & 1 & \\
\hline $\begin{array}{l}\text { Yes } \\
\text { Month of } \\
\text { sputum } \\
\text { conversion }\end{array}$ & $5(18.5)$ & $54(27.0)$ & $0.65(0.26-1.64)$ & 0.357 \\
\hline $0-2$ months & $9(39.1)$ & $76(41.8)$ & 1 & \\
\hline$>2$ months & $9(39.1)$ & $46(25.3)$ & $0.92(0.33-2.62)$ & 0.885 \\
\hline $\begin{array}{l}\text { Unable to } \\
\text { produce sputum }\end{array}$ & $9(39.1)$ & $60(33.0)$ & $1.23(0.52-2.94)$ & 0.638 \\
\hline
\end{tabular}

At multivariable regression analysis, patients who were treated previously for DR-TB were 3.46 times (Adjust- ed prevalence Ratio: 3.46, $95 \%$ CI: 1.68 - 7.14) as likely to be non-adherent compared to those that had not been treated for DR-TB before (Table 5). 
Table 5: Multivariable regression analysis of factors associated with non-adherence to MDR-TB treatment at Mulago National Referral Hospital TB unit January 2012-May 2016

\begin{tabular}{lcc}
\hline & $\begin{array}{c}\text { Adjusted } \\
\text { Prevalence } \\
\text { Ratios (95\% CI) P- Value }\end{array}$ \\
$\begin{array}{l}\text { Previous DR-TB Treatment } \\
\text { No }\end{array}$ & 1 & \\
$\quad$ Yes & $3.46(1.68-7.14)$ & 0.001 \\
Treatment registration group & 1 & \\
$\quad$ New (N) & $0.43(0.10-1.78)$ & 0.245 \\
$\quad$ Relapse (Rp) & $1.77(0.76-4.12)$ & 0.186 \\
$\quad$ After loss to follow-up (Rt) & $0.86(0.27-2.72)$ & 0.803 \\
$\quad$ After failure of first treatment with & & \\
first-line drugs (F1) & & \\
$\quad$ After failure of retreatment regimen & $0.44(0.09-2.05)$ & 0.295 \\
with first line drugs (F2) & & 0.306 \\
$\quad$ After failure of regimen with & $1.85(0.57-6.05)$ & \\
second-line drugs (F4) and others & & \\
\hline
\end{tabular}

\section{Discussion}

This study set out with the aim of determining to what extent MDR-TB patients previously treated at MNRH under the national TB program in Uganda adhered to treatment. The results of the study showed that $11.9 \%$ of the patients are non-adherent to their treatment. This finding is lower than those of other studies done in different settings that reported non-adherence levels between $18-33 \%{ }^{16-21}$. The differences in rates of non-adherence may be due to different methodologies and definitions used. The findings in our study may also be due to lack of social support ${ }^{22,23}$, treatment drug side effects, forgetting to take medication, being away from home, missing date of appointment, lack of transportation cost to treatment center, poor communication between patient and healthcare providers, and stock out of medicines.

Participants who had been treated for DR-TB previously were 3.46 times more likely to be non-adherent to MDR-TB treatment. Previous studies have described the role of prior susceptible TB treatment in the development of MDR-TB ${ }^{24}$ but have not described its impact on adherence among those being retreated. It is very likely that the same factors like poor social support that lead patients to default on the first DR-TB treatment episode could also be carried into subsequent retreatment episodes and thus influence their adherence. MDR-TB treatment programs therefore must take extra care when dealing with patients that have been treated for DR-TB before. Adherence programs need to incorporate this consideration. The patients that are potential repetitive defaulters pose an extra risk to the efforts of curbing the TB epidemic. Our study participantsere at risk of developing X-DR during the period under review despite them being sensitive to all second line MDR-TB drugs after DST at the start of the treatment. They may also be more likely to continue spreading the disease in the communities where they live ${ }^{20}$.

\section{Strength}

The strength of the current study is the utilization of programmatic data in assessing non-adherence and associated factors. Unlike in clinical trials where the characteristics of those participants are highly selective, routinely collected data gives us the true picture of what is happening in the real world. The inferences made from this data can be used to develop interventions that are 
relevant to specific contexts and environments in which the patients live on a daily basis. When further developed and analyzed from the patient's perspective it can be used to inform policy makers on how quality of care can be improved and how patient education tools can be developed to fit patient needs.

\section{Limitations}

This study was unable to assess the impact of factors that are not routinely collected within the National Tuberculosis treatment program. Factors such as the patient's level of education, distance from hospital, smoking and lack of awareness of the treatment duration that have been found to significantly impact on adherence in other studies could not be assessed in this study because data was not available. ${ }^{4}$ The quantitative nature of the study focuses on quantifying adherence and associated factors. It thus does not permit the investigation of qualitative patient factors such as self-motivation, counselling experiences, family and nutritional support, that have been previously found to be key drivers of adhrence to MDR-TB treatment ${ }^{22}$. The exclusion of some records of patients missing information on key independent variables under study may have minimally biased our results. However, MNRH TB unit is the largest and receives patients from across Uganda.

\section{Conclusion}

1 in 10 MDR-TB patients treated at the Mulago National Referral Hospital in Kampala, Uganda is non-adherent to treatment. History of previous DR-TB treatment was associated with non-adherence to TB treatment in our cohort.

\section{Recommendations}

The National MDR-TB treatment program should strengthen adherence counselling, provide consistent second line DST during treatment and close monitoring for patients that have been previously treated for MDRTB. Secondly, because such patients have been exposed to sub-optimal doses of the treatment regimen, they are very likely to develop Extensively Drug Resistant Tuberculosis, which is more lethal. Therefore, to protect the public, TB treatment programs should focus on promoting adherence to MDR-TB treatment and ensuring strict management for those that have been treated before.

The TB enablers program that is currently being used to defray catastrophic costs for MDR-TB patients should also incorporate aspects of adherence, patients that adhere to treatment should be given extra incen- tives in order to encourage the non-adherent ones to adhere more.

The National MDR-TB program and the Ministry of health should take up the shorter treatment regimens that have been found to be equally effective. Though there is currently no evidence that the shorter treatment regimens will improve on adherence, reducing the treatment episode length will give patients more confidence that they can complete treatment, reduce the cost associated with accessing treatment and possibly the side effects associated with prolonged treatment periods.

\section{Funding}

MakCHS - UCBerkeley- Yale Pulmonary Complications of AIDS Research Training (PART) Program, NIH D43TW009607 through the Fogarty International Center, made this research possible. Its contents are solely the responsibility of the authors and do not necessarily represent the official views of FIC or NIH.

\section{Author contributions}

$\mathrm{CB}$ conceived the idea and wrote the paper in conjunction with JM, MSN and RK collected the data, JM designed and conducted the analysis; SA and AK guided the approach, data collection and analysis tools design.

\section{Acknowledgements}

We acknowledge the support of the National Tuberculosis and Leprosy Program (NTLP) and the staff of Ward 5 \& 6 at Mulago National Referral Hospital.

\section{Consent to publish}

All authors read and provided consent to publish this manuscript.

\section{Conflict of interest}

None declared.

\section{References}

1. World Health Organization. Health in 2015: From MDGs to SDGs. Geneva: World Health Organization; 2015.

2. Busza J, Dauya E, Bandason T, Simms V, Chikwari $\mathrm{CD}$, Makamba M, et al. The role of community health workers in improving HIV treatment outcomes in children: lessons learned from the ZENITH trial in Zimbabwe. Health Policy Plan. 2018;33(3):328-34.

3. World Health Organization. Framework for implementing the "End TB Strategy" in the African Region. 2016-2020. 2017.

4. GBD Tuberculosis collaborators. Global, regional, 
and national burden of tuberculosis, 1990-2016: results from the Global Burden of Diseases, Injuries, and Risk Factors 2016 Study. The Lancet Infectious Diseases. 2018;18(12):1329-49.

5. World Health Organization. Global tuberculosis report 2019. Geneva: World Health Organization; 2019.

6. Modongo C, Sobota RS, Kesenogile B, Ncube R, Sirugo G, Williams SM, et al. Successful MDR-TB treatment regimens including amikacin are associated with high rates of hearing loss. BMC Infectious Diseases. 2014;14(1):542.

7. Kathryn S, Sydney R, Kate S, Neil M, Lawrence L, Ian $\mathrm{S}$, et al. Costs of inpatient treatment for multi-drug-resistant tuberculosis in South Africa. Tropical Medicine \& International Health. 2013;18(1):109-16.

8. World Health Organization. Guidelines for Programmatic Management of Multi-Drug Resistant Tuberculosis 2011 Update. Geneva, Switzerland: World Health Oragnization; 2011.

9. Sturdy A, Goodman A, Jose RJ, Loyse A, O'Donoghue M, Kon OM, et al. Multidrug-resistant tuberculosis (MDR-TB) treatment in the UK: a study of injectable use and toxicity in practice. The Journal of antimicrobial chemotherapy. 2011;66(8):1815-20.

10. Peloquin CA, Berning SE, Nitta AT, Simone PM, Goble M, Huitt GA, et al. Aminoglycoside toxicity: daily versus thrice-weekly dosing for treatment of mycobacterial diseases. Clinical infectious diseases : an offcial publication of the Infectious Diseases Society of America. 2004;38(11):1538-44.

11. Awofeso N. Anti-tuberculosis medication side-effects constitute major factor for poor adherence to tuberculosis treatment. Bulletin of the World Health Organization. 2008;86(3):B-D.

12. Amuha MG, Kutyabami P, Kitutu FE, Odoi-Adome $\mathrm{R}$, Kalyango JN. Non-adherence to anti-TB drugs among TB/HIV co-infected patients in Mbarara Hospital Uganda: prevalence and associated factors. African Health Sciences. 2009;9 Suppl 1:S8-15.

13. Kirenga BJ, Levin J, Ayakaka I, Worodria W, Reilly N, Mumbowa F, et al. Treatment Outcomes of New Tuberculosis Patients Hospitalized in Kampala, Uganda: A Prospective Cohort Study. PloS One. 2014;9(3):e90614.

14. Adane AA, Alene KA, Koye DN, Zeleke BM. Non-adherence to anti-tuberculosis treatment and determinant factors among patients with tuberculosis in northwest Ethiopia. PloS One. 2013;8(11):e78791.

15. Setia MS. Methodology Series Module 3: Cross-sectional Studies. Indian Journal of Dermatology. 2016;61(3):261-4.
16. O'Donnell MR, Wolf A, Werner L, Horsburgh CR, Padayatchi N. Adherence in the treatment of patients with extensively drug-resistant tuberculosis and HIV in South Africa: a prospective cohort study. J Acquir Immune Defic Syndr. 2014;67(1):22-9.

17. Woimo TT, Yimer WK, Bati T, Gesesew HA. The prevalence and factors associated for anti-tuberculosis treatment non-adherence among pulmonary tuberculosis patients in public health care facilities in South Ethiopia: a cross-sectional study. BMC Public Health. 2017;17(1):269.

18. Jones-Lopez EC, Ayakaka I, Levin J, Reilly N, Mumbowa F, Dryden-Peterson S, et al. Effectiveness of the standard WHO recommended retreatment regimen (category II) for tuberculosis in Kampala, Uganda: a prospective cohort study. PLoS Med. 2011;8(3):e1000427. 19. Ibrahim LM, Hadejia IS, Nguku P, Dankoli R, Waziri NE, Akhimien MO, et al. Factors associated with interruption of treatment among Pulmonary Tuberculosis patients in Plateau State, Nigeria. 2011. Pan Afr Med J. 2014;17:78.

20. Brust JC, Gandhi NR, Carrara H, Osburn G, Padayatchi N. High treatment failure and default rates for patients with multidrug-resistant tuberculosis in KwaZulu-Natal, South Africa, 2000-2003. The International Journal of Tuberculosis and Lung Disease: The Official Journal of the International Union against Tuberculosis and Lung Disease. 2010;14(4):413-9.

21. Nellums LB, Rustage K, Hargreaves S, Friedland JS. Multidrug-resistant tuberculosis treatment adherence in migrants: a systematic review and meta-analysis. BMC Medicine. 2018;16(1):27.

22. Deshmukh RD, Dhande DJ, Sachdeva KS, Sreenivas AN, Kumar AMV, Parmar M. Social support a key factor for adherence to multidrug-resistant tuberculosis treatment. The Indian Journal of Tuberculosis. 2018;65(1):41-7.

23. Mekonnen HS, Azagew AW. Non-adherence to anti-tuberculosis treatment, reasons and associated factors among TB patients attending at Gondar town health centers, Northwest Ethiopia. BMC Res Notes. 2018;11(1):691-.

24. Lukoye D, Adatu F, Musisi K, Kasule GW, Were W, Odeke R, et al. Anti-tuberculosis drug resistance among new and previously treated sputum smear-positive tuberculosis patients in Uganda: results of the first national survey. PLoS One. 2013;8(8):e70763.

25. Carlson MDA, Morrison RS. Study Design, Precision, and Validity in Observational Studies. Journal of Palliative Medicine. 2009;12(1):77-82. 